\title{
Identifying the factors driving vegetation degradation and restoration in the desert, grassland, and forest regions of the Mongolian Plateau
}

\author{
Chunli Zhao ${ }^{1}$, Yan Yan ${ }^{2}$, Wenyong Ma³, Yuejing Rong ${ }^{1}$, and Yuan Quan ${ }^{2}$ \\ ${ }^{1}$ Research Centre for Eco-Environmental Sciences Chinese Academy of Sciences \\ ${ }^{2}$ Research Center for Eco-Environmental Sciences, Chinese Academy of Sciences \\ ${ }^{3}$ Beijing GEOWAY Software Co., Ltd.
}

June 25, 2020

\begin{abstract}
The Mongolian Plateau (MP) plays an important role in the global carbon cycle and has significant impacts on the ecological security of northeastern Asia. Affected by land degradation and desertification, the vegetation cover on the MP experiences major changes under the influence of human activity and climate change. In contrast to previous holistic studies on the MP, this research focusses on the features of vegetation cover and divides the MP into three subregions (desert, grassland, and forest) to analyze vegetation dynamics and identify the driving factors behind vegetation change in this region. The residual analysis method is used and its "errors" are discussed. The results show the following. 1) The area of vegetation restoration is larger than the area experiencing vegetation degradation, and, overall, vegetation is greening and vegetation degradation is tending to reverse on the MP. 2) The ranking of vegetation change intensity is forest $>$ grassland $>$ desert subregions. 3) Climate change is the principal control on vegetation restoration across the whole MP, including the grassland and forest regions. Human activity similarly affects both vegetation restoration and degradation, but the effect of human activity is greater than that of climate change in the desert region. This research confirms that vegetation restoration activity is effective in the desert subregion of the MP.
\end{abstract}

\begin{abstract}
The Mongolian Plateau (MP) plays an important role in the global carbon cycle and has significant impacts on the ecological security of northeastern Asia. Affected by land degradation and desertification, the vegetation cover on the MP experiences major changes under the influence of human activity and climate change. In contrast to previous holistic studies on the MP, this research focusses on the features of vegetation cover and divides the MP into three subregions (desert, grassland, and forest) to analyze vegetation dynamics and identify the driving factors behind vegetation change in this region. The residual analysis method is used and its "errors" are discussed. The results show the following. 1) The area of vegetation restoration is larger than the area experiencing vegetation degradation, and, overall, vegetation is greening and vegetation degradation is tending to reverse on the MP. 2) The ranking of vegetation change intensity is forest > grassland $>$ desert subregions. 3) Climate change is the principal control on vegetation restoration across the whole MP, including the grassland and forest regions. Human activity similarly affects both vegetation restoration and degradation, but the effect of human activity is greater than that of climate change in the desert region. This research confirms that vegetation restoration activity is effective in the desert subregion of the MP.
\end{abstract}

Keywords : vegetation dynamics, climatic factors, RESTREND method, Mongolian Plateau, Driving factors 


\section{INTRODUCTION}

Land degradation can cause global environmental change via its impact on the terrestrial ecosystem, hydrologic cycle, energy exchange, and other processes, and represents a major global environmental problem that encompasses regional ecological security and food security. The relationships that link fragile ecoenvironments, land degradation, and poverty can restrict regional socio-economic development (Gao and Mao, 2003; Tong and Long, 2003). The Committee for Development Policy (CDP) has developed a series of Sustainable Development Goals (SDGs) and SDG 15 ("Life on Land") aims to combat desertification, restore degraded land and soil, and strive to achieve a land-degradation-neutral world by 2030 (SDGs, 2015).

Land degradation is a complex phenomenon that is associated with a reduction in land productivity, especially in arid and semi-arid areas (Kassas, 1995). Although land degradation occurs across arable land, grassland, forests, and other areas with production capability (Liu, 1995), the essence of land degradation is desertification (UNCCD, 1994). Yang (1997) proposed that land degradation can be seen as a reduction in the biological or economic production capacity of land caused by excessive human activity, and that the primary problem that drives land degradation is desertification. Zhu (1994) defined land degradation as the decline of land productivity and the evolution of other landscapes towards desertification, caused by unmitigated economic activity in a fragile ecological environment. Zhou and $\mathrm{Pu}$ (1996) suggested that land degradation includes desertification, which is a part of land degradation. However, these different interpretations of what constitutes land degradation all include the central tenet that land degradation causes a decrease in the land productivity. Researchers have reached a consensus that land degradation has a serious impact on global economic and social development, which will be difficult to recover from over a short period of time (Okin et al., 2001). In addition, without any control measures, land degradation will accelerate, and the cost of later rehabilitation will increase exponentially (Glantz and Orlovsky, 1983).

Land degradation is driven by a combination of human activity and climate change. Global warming has decreased the growth of vegetation in some regions (Wieder et al., 2015), and reduced vegetation productivity to some extent (Asseng et al., 2015). Temperature, precipitation, wind speed, and other climatic factors influence regional soil, vegetation, and other surface characteristics, leading to climate-related vegetation degradation (Guo et al., 2012). Compared with climatic factors, it is difficult to quantify the direct impact of human activity on vegetation change. Rapid population growth, industry development, animal husbandry, and ecological restoration projects all have some impact on vegetation change. All anthropogenic activity, such as deforestation, mineral exploitation, and improper land use, as well as emissions of industrial and domestic waste, and greenhouse gas emission, break the balance of natural ecosystems and result in serious ecological and environmental problems (Fleskens and Stringer, 2014; Liu Q. et al., 2014).

The Mongolian Plateau (MP) is located in the hinterland of Eurasia, which spans arid, semi-arid, and semi humid climate regions. This unique geographical location makes the eco-environment of this region especially vulnerable to interference from external factors. The MP is often used to study land degradation because the region is sensitive to both human activity and climate change, and also faces the problems of desertification and vegetation degradation (Zhang et al., 2008). The MP plays an important role in the global carbon cycle, and its ecosystem status and changes have an important impact on the environment of the whole of northeastern Asia (Zhang, et al., 2009; Zhang, et al., 2003). Changes to the eco-environment of the MP will affect carbon sinks in the surrounding regions, as well as further afield, through dust transmission. In recent decades, in the context of global warming and excessive reclamation, overgrazing, poor protection, soil degradation, and desertification of the MP have increased, resulting in severe pressure on the ecological environment (Liu, et al., 2016). Consequently, financial resources and policy measures have been implemented in an attempt to protect and improve the ecological environment of the MP, and these countermeasures have been relatively effective. However, soil degradation and desertification in the region remain very serious problems, and directly threaten the ecological security of China and the whole of East Asia (Mi et al., 2015; Fujiwara et al., 2007). Using the MP as our research focus to study vegetation change has important and urgent practical significance for regional vegetation restoration and ecological security in Southeast Asia.

There are regional differences in the extent and impact of the various factors that influence vegetation change. 
Smaller scale causes of vegetation degradation on the MP have been somewhat overlooked due to the focus on larger regional effects in previous research. Therefore, it is necessary to develop a clearer picture of the factors that drive vegetation dynamics in the different types of ecosystems on the plateau. In this study, we aim to determine the nature of vegetation change and identify its key drivers across the whole plateau and in each of its subregions (i.e., the desert, grassland, and forest subregions).

\section{MATERIALS AND METHODS}

\subsection{Study area}

From southwest to northeast on the MP, the pattern of vegetation cover grades from desert to grassland to forest, and the plateau shows dramatic spatial and temporal variations in land cover (Liu, 1993). According to the Global Aridity Index dataset, which is based on UNEP's (1997) aridity degree classification, the MP can be divided into an arid area (including an extremely arid area), a semi-arid area, and a semi humid area (including a humid area). The desert, grassland, and forest are located mainly in the arid, semi-arid, and semi humid areas, respectively (Miao et al., 2014). Although climate change, especially precipitation changes, have affected the boundaries of these climate zones to some extent (Jeong et al., 2011; Sternberg et al., 2015), they have remained relatively stable on the whole. Here, we divided the MP into three subregions, namely desert, grassland, and forest, in reference to the UNEP (1997) aridity degree divisions. The distribution of land cover is shown in Figure 1.

The desert subregion (DSR) is located in the southwest of the MP and has an annual mean precipitation of $<200 \mathrm{~mm}$. The main land cover is bare land and sparse vegetation (65\%) and grassland (32\%). The grassland subregion (GSR) is located in the central and northern portions of the plateau, and receives annual precipitation of between 200 and $400 \mathrm{~mm}$. This is a subregion of the Eurasian grassland, which is one of the largest grassland ecosystems in the world (Batima and Dagvadorj, 2000). The main land cover is grassland (90\%) and farmland (4\%). The forest subregion (FSR) receives annual precipitation of approximately $400 \mathrm{~mm}$, and the forest landscape is fragmented across this region (Bohannon, 2008). The main land cover in this region is grassland (41\%), forest (34\%), and farmland (18\%).

\subsection{Data}

\section{1) Land Cover}

We obtained the land cover data from the MCD12Q1 dataset (Collection 5.1). These data have a spatial resolution of $500 \times 500 \mathrm{~m}$, cover the period between 2001 and 2015, and can be downloaded from the USGS Land Processes Distributed Active Archive Center. Based on the vegetation characteristics and our research objectives, here, we selected the land coverage classification developed by the Global Land Cover by National Mapping Organizations (GLCNMO).

\section{2) NDVI}

The normalized vegetation index (NDVI) is a ratio parameter derived from the reflectance in the near-infrared and infrared bands of remote sensing images, which can be used to determine vegetation coverage, biomass, and the leaf area index (Geerken et al., 2005; Dorigo et al., 2007). The NDVI data used in this study were obtained from NASA's Land Processes Distributed Active Archive Center (LPDAAC). We selected MOD13C2 (Collection 6) with a spatial resolution of $0.05^{\circ} \times 0.05^{\circ}$ sampled monthly between 2000 and 2015. The wavelengths of the near-infrared and red bands were $0.84-0.88$ and $0.62-0.67 \mu \mathrm{m}$, respectively.

\section{3) Actual net primary productivity (NPP-a)}

The actual net primary productivity (NPP-A) data for the period between 2000 and 2014 were obtained from the MOD17A3 product (Collection 5.5), which is provided by the NTSG (Numerical Terradynamic Simulation Group) from the University of Montana. We converted the NPP-A units to $\mathrm{g} \cdot \mathrm{C} \cdot \mathrm{m}^{-2} \cdot \mathrm{yr}^{-1}$. The blank (white) areas in Figure 2 indicate an absence of $\mathrm{NPP}_{-\mathrm{A}}$ data. 


\section{4) Potential net primary productivity (NPP-p)}

We used the Thornthwaite model to calculate the potential NPP (NPP-P) (Lieth and Box, 1972) as follows: $\mathrm{NPP}_{p}=3000 \times\left[1-\exp ^{-0.0009695(V-20)}\right]$,

where $V$ is the annual actual evapotranspiration $(\mathrm{mm})$, and NPP-P is measured in units of $\mathrm{g} \cdot \mathrm{C} \cdot \mathrm{m}^{-2} \cdot \mathrm{yr}^{-1}$.

The annual actual evapotranspiration data were retrieved from the MOD16A3 dataset of the NTSG, in which the evapotranspiration values are determined using the Penman-Monteith equation (Mu et al., 2007). The parameter used to estimate the NPP-p; i.e., the actual evapotranspiration, depends on solar radiation, temperature, precipitation, air pressure, and wind speed. Blank spaces on the evapotranspiration map (Figure 2) indicate an absence lack of data.

\subsection{Methods}

\section{1)Linear regression model}

We used linear trend analysis of the NDVI, NPP-A, NPP-P, and NPP residuals time series to investigate vegetation growth. The slope $(a)$ was used to express the change trend, and the $\mathrm{p}$ value was used to express the significance level of the change. The linear trend analysis was then extended to a grid scale. We calculated the slope according to Dai et al. (2014) as follows:

$a=\frac{\sum_{i=1}^{n}\left(x_{i}-x\right)\left(y_{i}-y\right)}{\sum_{i=1}^{n}\left(x_{i}-x\right)^{2}}$,

where $a$ is the trend (slope) of the change, with a positive (negative) value indicating an increasing (decreasing) vegetation trend. Taking NDVI as an example, $x$ is the average NDVI value, $x_{i}$ is the regional average NDVI value in the $i^{\text {th }}$ year, and $y$ is the year. We classified the resultant slope values into four categories: significant increase $(a>0, P<0.05)$; non-significant increase $(a>0, P>0.05)$; significant decrease $(a<0$, $P<0.05)$; non-significant decrease $(a<0, P>0.05)$.

\section{2) The RESTREND method}

We used the residual trend analysis (RESTREND) method to explore the degree and scope of the effect of anthropogenic and climatic factors on regional vegetation (Evans and Geerken, 2004; Ma et al., 2017).

$\mathrm{NPP}_{-\mathrm{A}}$, which is directly observed by remote sensing and selected from a set of remote sensing datasets, monitors the real growth conditions of local vegetation. NPP-A records the combined effects of human activity and climate change.

$\mathrm{NPP}_{-\mathrm{P}}$ is calculated from the actual annual evapotranspiration measurements, and this index represents the NPP value under ideal conditions with no human activity; that is, the $\mathrm{NPP}_{-\mathrm{P}}$ value influenced only by climatic factors. The change in $\mathrm{NPP}_{-\mathrm{P}}$ can be interpreted as reflecting a climatic control on vegetation dynamics. A positive value of the $\mathrm{NPP}_{-}$p change rate indicates that climate change is beneficial to vegetation recovery, whereas a negative value indicates a detrimental effect.

The residuals of (i.e., differences between) the NPP- ${ }_{A}$ and $\mathrm{NPP}_{-\mathrm{P}}$ values are defined as the residual NPP value (NPP-RES) and can be interpreted as reflecting the influence of human activity on the value of NPP:

$\mathrm{NPP}_{-\mathrm{RES}}=\left(\mathrm{NPP}_{-\mathrm{P}}\right)-\left(\mathrm{NPP}_{-\mathrm{A}}\right)$

Using the RESTREND method, the NPP-p reflects the absence of anthropogenic influence, while the NPPRES value represents only the extent to which human activity contributes to or damages regional vegetation recovery, and is interpreted in terms of the anthropogenic influence on vegetation dynamics. A positive value of the NPP-RES regression slope indicates that human activity has been conducive to vegetation recovery, whereas a negative value indicates that human activity has caused degradation.

The slope of the linear regression fit of the NDVI, NPP-P, and NPP-RES time series can be either $>0$ or $<0$. Taking all permutations of the NDVI, NPP-P, and NPP-RES slope values into account, we can generate 
eight potential scenarios that reflect the main driving factors controlling vegetation change and these are detailed in Table 1.

\section{Results}

\subsection{Regional NDVI dynamics}

Vegetation recovered on the MP between 2000 and 2015, and the area in which restoration was statistically significant exceeded that in which degradation predominated in each subregion during three equal subperiods (Table 2).

\subsubsection{DSR}

In the DSR, the overall change was more severe for the whole 2000-2015 period than that in each subperiod. The NDVI area with a statistically significant change (significant restoration and degradation) is larger than the sum of the NDVI changes from each period. The significant restoration area is more than $25 \%$ in the DSR between 2000 and 2015, and the vegetation recovery area is always larger than the degradation area during each period. This shows that vegetation activity was enhanced and the DSR experienced a period of vegetation restoration (Figure 3).

\subsubsection{GSR}

In the GSR, the extent and proportion of vegetation change over the entire period between 2000 and 2015 was greater than that in each subperiod (Figure 4). The significantly recovered area was more than $31 \%$ of the GSR. The area with vegetation restoration was always larger than that with degradation in any investigated time period. This shows that, overall, vegetation recovery occurred in the GSR over the study period.

\subsubsection{FSR}

Vegetation dynamics were more intense during the entire 2000-2015 period than in each subperiod in the FSR (Figure 5). The significant restoration area was more than 50\% in the FSR. The significant recovery area was larger than that of the significant degradation area in each period, which shows that overall vegetation recovery occurred in the FSR over our study period.

\section{4) Comparison of the three subregions}

The most active period of vegetation dynamics in the DSR was 2010-2015, with $9.58 \%$ of the statistically significant area changes in this region. The most active period of vegetation dynamics in the GSR and FSR was 2000-2005, which accounted for $9.33 \%$ and $18.78 \%$ of significantly changed areas, respectively, of the total areas of each subregion.

The overall trend across the three subregions was of vegetation recovery. The ranking of areas with significant restoration was: FSR $(51.52 \%)>$ GSR $(31.88 \%)>$ DSR $(25.73 \%)$; and the ranking of areas with significant degradation was: FSR $(2.57 \%)>$ DSR $(0.53 \%)>$ GSR $(0.33 \%)$. This shows that the FSR is the subregion with the most fluctuations in vegetation change on the MP, with the highest proportion of the area experiencing significant recovery and degradation. The GSR and DSR remained relatively stable, showing an overall improving trend. On the whole, the improvement indicated by the NDVI occurred mostly in the south and east of the study area.

\subsection{Driving factors of vegetation change}

Our analysis of the different driving factors that affect vegetation dynamics showed that the highest proportion of vegetation restoration area occurred in the FSR (39.24\%), then the GSR (23.03\%), and finally the DSR (1.88\%). The highest proportion of vegetation degradation was the FSR (9.48\%), followed by the GSR $(6.69 \%)$, and then the DSR (1.06\%). In general, the area with significant vegetation restoration was larger than the area with significant vegetation degradation. At the same time, the intensity of regional vegetation 
change was also FSR $>$ GSR $>$ DSR. The FSR was the area that experienced the most dramatic vegetation change on the MP, and the DSR showed the least change in vegetation (Figure 6).

These results are broadly consistent with vegetation dynamics on the MP that were based on our NDVI evaluation in section 3.1 .

Vegetation restoration under climatic influence was the main driving force behind vegetation restoration in the GSR and FSR, accounting for $18.24 \%$ and $13.98 \%$, respectively, in each subregion. Human activity had a similar effect on vegetation restoration and degradation: $1.02 \%$ and $0.94 \%$, respectively, in the DSR; $6.63 \%$ and $4.41 \%$, respectively, in the GSR; and $9.30 \%$ and $12.21 \%$, respectively, in the FSR. Only the effect of human activity on vegetation restoration in the DSR was greater than that of climate. This indicates that some vegetation restoration initiatives in this area are generating effective outcomes (Table 3 ).

\section{Discussion}

\subsection{Errors in the residual method}

The vegetation change trend, evaluated with respect to the driving factors and NDVI indicator, showed restoration in the MP and each in subregion, but there were some differences in the restoration ratios between those two evaluation methods. This section focuses on this phenomenon, which can partly explain the "Errors" listed in Tables 1 and 3.

We classified possible scenarios as A, B, C, and D (see Table 1). Scenario A occurs when the negative effect of climate change is greater than the positive effect of human activity, resulting in vegetation degradation. Scenario $\mathrm{C}$ occurs when the negative effect of human activity is less than the positive effect of climate change, resulting in vegetation recovery.

Results yielding scenarios B and D were defined as "Errors" here. NDVI and actual NPP are both indexes that can reveal and track vegetation growth and dynamics, and these two indexes are closely correlated. For example, the research of De et al. (2013) captured the spatial pattern of NPP, and the global trend of NPP is consistent with the NDVI for the same period of time.

Rashid et al. (2016) revealed that about $68 \%$ of the global land area has positive NPP values with an increasing trend, which corresponds closely to the $67 \%$ of the MP land area with positive NDVI values and an increasing trend. This phenomenon provides theoretical support for our use of NDVI and NPP in the RESTREND method to validate the driving forces of vegetation dynamics. However, there are inconsistencies between NDVI and NPP values in some regions and situations. For example, if grassland or forest is transformed into farmland/plantations, the actual NPP could show a huge increase because of artificial fertilization and irrigation. Consequently, it is possible that changes in NDVI $<0$ and changes in $\mathrm{NPP}_{-\mathrm{RES}}>0$ could co-occur if $\mathrm{NPP}_{-\mathrm{P}}$ increases but $\mathrm{NPP}_{-\mathrm{A}}$ increases more, and vice versa. We believe that this can explain part of the error scenarios outlined above from a data perspective.

\subsection{Discussion of different vegetation types}

Here, we compared vegetation restoration and degradation on the MP, and found that the relative intensity of vegetation change in the three subregions was: FSR $>$ GSR $>$ DSR. For comparison, we considered changes in different types of vegetation cover from previous research over the same time period. Research that focused on the grassland and forest regions of East Asia showed that the mean value of carbon use efficiency (CUE) was grassland $>$ farmland $>$ forest $>$ shrub during the period 2000-2013 in China (Liu et al., 2019). That is, the highest CUE was found in grassland, and the increase of CUE was caused mainly by increases in precipitation, while increases in temperature inhibited the vegetation CUE. Liu et al. (2020) studied the response of the NDVI on different types of vegetation cover influenced by climate change on the Loess Plateau of China. Their results showed that the NDVI of different vegetation covers does not correspond to the size of the occupied area, and that the increasing trend of the NDVI in the forested areas 
was greater than that in the grassland areas (the grass area is larger than forested area), which is similar to the conclusion of this study.

Other spatiotemporal studies reported different results. De et al. (2013) described the relationship between vegetation and climate over the period between 1981 and 2008 based on meteorological indicators, and found that climate can explain nearly $54 \%$ of vegetation change.

The impact of vegetation change on climate is concentrated mainly in areas of desertification and surrounding areas. Charney $(1977,2006)$ explored the possible impact of vegetation dynamics on climate, and pointed out that desertification increases the surface albedo, reduces the soil moisture content, and reduces the surface roughness. This leads to reduced precipitation, which would be followed by deterioration of the vegetation and soil. Vegetation recovery becomes more difficult under these conditions (Nicholson et al., 1988), and these impacts can then extend to the surrounding areas (Xue, 1993, 1996). The expansion of a desert region may strengthen regional climate change, aggravating land degradation. Grassland has a greater ecological elasticity to climate change compared with desert areas (John et al., 2013). Peng et al. (2012) proposed that, compared with forest ecosystems in humid areas, grassland ecosystems in semi-arid and arid areas are more sensitive to drought. Desert grassland is more sensitive to drought compared with typical grassland and meadow grassland (Bailing et al., 2018). Therefore, there may be a negative feedback relationship between vegetation change and climate in desert areas. Here, we observed that the DSR has the slowest observed vegetation restoration.

Bao et al. (2015) studied vegetation dynamics and its response to regional climate change in Mongolia, and showed that continuous warming is likely to be the main factor driving the reversal of the NDVI trend. Furthermore, climate-related vegetation reduction and related potential desertification may aggravate other environmental problems in East Asia (e.g., sandstorms).

The vegetation restoration associated with human activity in the desert is inseparable from vegetation restoration measures and projects formulated by local governments. We list the policy measures and their impacts on regional vegetation restoration after 2000 in Table 4.

Therefore, we conclude that the desert is the region of the MP most in need of vegetation restoration, although it is also currently the area with the slowest rate of vegetation restoration. Restoration of desert areas is effective, and the desert should be a high priority area for improving vegetation restoration.

\section{Conclusions}

Our evaluation of vegetation dynamics and the associated driving factors across the MP and its subregions has revealed the following. The proportion of each subregion that experienced vegetation restoration during the study period was greatest in the FSR, followed by the GSR, with the DSR showing the least restoration. From the perspective of driving factors, overall, climate change was conducive to vegetation restoration, whereas the amounts of vegetation restoration and degradation caused by human activity were relatively similar. From the regional perspective, the extent of restoration caused by climate change in the FSR and GSR was far greater than that caused by human activity, but in the DSR, restoration by human activity exceeded that related to climate change. Restoration in the DSR was slower than that in the FSR and GSR. As a result, the DSR should be a priority area for policy and investment. Human activity was the main driving force behind vegetation restoration in the DSR, and thus the restoration effect of human activity is still effective in this region. China's government should use "the Belt and Road Initiative" (Liu, 2015) to cooperate and establish links with Mongolia and other countries to assist desertification control and curb regional land degradation.

Acknowledgments: This research was supported by National Key R\&D Program of China (No. 2018YFC0806900).

Conflicts of Interest: The authors declare no conflict of interests. 


\section{Reference}

Asseng, S., Ewert, F., Martre, P., et al. (2015). Rising temperatures reduce global wheat production. Nature Climate Change, 5(2): 37-64.

Bailing, M., Zhiyong, L., et al. (2018). Temporal and spatial heterogeneity of drought impact on vegetation growth on the Inner Mongolian Plateau. The rangeland journal, 40(2): 113-128.

Bao, G., Bao, Y., Sanjjava, A., et al. (2015). NDVI-indicated long-term vegetation dynamics in Mongolian and their response to climate change at biome scale. International journal of climatology, 35(14):4923-4306.

Batima, P., Dagvadorj, D. (2000). Climate Change and Its Impact in Mongolia. Ulaanbaatar, JEMR Publishing, Mongolia.

Bohannon, J. (2008). The Big Thaw Reaches Mongolia's Pristine North.Science, 7, 319(5863): 567-568.

Casa, R., Varella, H., Buis, S., et al. (2012). Forcing a wheat crop model with LAI data to access agronomic variables: Evaluation of the impact of model and LAI uncertainties and comparison with an empirical approach. European Journal of Agronomy, 37(1) : 1-10.

Charney, JG. (2006). Dynamics of deserts and drought in the Sahel.Quarterly journal of the royal meteorological society, 101(428):193-202.

Charney, JG., Quirk, WJ., et al. (1977). A comparative study of the effects of Albedo change on drought in semi-arid regions. Journal of the atmospheric sciences, 34(12): 1366-1385.

Chen, J., John, R., Shao, C., et al. (2015). Policy shifts influence the functional changes of the CNH systems on the Mongolian Plateau.Environmental Research Letters, 10: 085003.

Dai, L., Zhang, L., Wang, K. (2014). Vegetation changing trend and its affecting factors in Mongolian Plateau. Bulletin of Soil and Water Conservation, 34(5): 218-225. Doi:10.13961/j.cnki.stbctb.2014.05.047

De, JR., Schaepman, ME., Furrer, R., et al. (2013). Spatial relationship between climatologies and changes in global vegetation activity. Glob. Chang. Biol, 19, 1953-1964.

Dorigo, W., Zurita-Milla, et al. A review on reflective remote sensing and data assimilation techniques for enhanced agroecosystem modeling.International Journal of Applied Earth Observation 8 Geoinformation, 2007, 9(2): 165-193.

Evans, J., Geerken, R. (2004). Discriminating between climate and human-induced dryland degradation. Journal of Arid Environments, 57(4): 535-554.

Fleskens, L., Stringer, L. (2014). Land management and policy responses to mitigate desertification and land degradation. Land Degradation 83 Development, 25(1): 1-4.

Fujiwara, H., Fukuyama, T., Shirato, Y., et al. (2007). Deposition of atmospheric 137Cs in Japan associatedwith the Asian dust event of March 2002. Science of The Total Environment, 384(1-3): 306-315.

Gao, Q., Mao, HY. (2003). GIS-based study on the ecological-economic regionalization of Yunyang Country in Three Gorges reservoir area.Acta ecological sinica, 23(1): 74-81.

Geerken, R., Batikha, N., et al. (2005). Differentiation of rangeland vegetation and assessment of its status: field investigations and MODIS and SPOT VEGETATION data analyses. International Journal of Remote Sensing, 26(26): 4499-4526.

Glantz, M., Orlovsky, N. (1983). Desertification: a review of the concept. Desertification Control Bulletin, 9: $15-22$.

Guo, Q., Hu., Z, Li, S., et al. (2012). Spatial variations in aboveground net primary productivity along a climate gradient in Eurasian temperate grassland: effects of mean annual precipitation and its seasonal distribution. Global Change Biology, 18(12):3624-3631. 
Jeong, S., Ho, C., Brown, M., et al. (2011). Browning in desert boundaries in Asia in recent decades. Journal of Geophysical Research Atmospheres, 116(D2): 3-25.

John, R., Chen, JQ., Qu-Yang, ZT., et al. (2013). Vegetation response to extreme climate events on the Mongolian Plateau from 2000 to 2010.Environmental research letters, 8: 0350033

Kassas, M. (1995). Desertification: a general review. Journal of Arid Environments, 30(2): 0-128.

Lieth, H., Box, E. (1972). Evapotranspiration and primary productivity. In: Thornthwaite W ed. Memorial Model. Publicatios in Climatology, 25: 37-46.

Liu, D., Chen, Y., Cai, W., et al. The contribution of China's Grain to Green Program to carbon sequestration. Landscape Ecology, 2014, 29(10): 1675-1688.

Liu, H. (1995). Type and characteristics of land degradation and countermeasures in China. Resources science, 17(4): 26-32.

Liu, J., Wen, ZM., Gang, CC. (2020). Normalized difference vegetation index of different vegetation cover types and its responses to climate change in the Loess Plateau. Acta Ecologica Sinica, 40(2):678-691. DOI: $10.5846 /$ stxb201901090082

Liu, Q., Yang, Y., Tian, H., et al. (2014). Assessment of human impacts on vegetation in built-up areas in China based on AVHRR, MODIS and DMSP_OLS nighttime light data, 1992-2010. Chinese Geographical Science, 24(2): 231-244.

Liu, WD. (2015). Scientific understanding of the Belt and Road Initiative of China and related research themes. Progress in Geography, 34(5): 538- 544. doi: 10.11820/dlkxjz.2015.05.001

Liu, YY., Wang, Q., Yang, R., et al. (2019). Spatiotemporal dynamic of vegetation carbon use efficiency and its relationship with climate factors in China during the period 2000-2013. Research of soil and water conservation. Doi: 10.13869/j.cnki.rswc.2019.05.041

Liu, ZF., Wang, R., Yao, ZJ. (2016). Air temperature and precipitation over the Mongolian Plateau and assessment of CMIP 5 climate models. Resources Science, 38(5): 956-969. DOI:10.18402/resci.2016.05.15

Liu, ZL. (1993). Analysis of Mongolian Plateau landscape ecology. Journal of arid and resources and environment,3(7): 256-261. Doi:10.13448/j.cnki.jalre.1993.z1.074

Ma, WY., Wang, XM., Zhou, N. (2017). Relative importance of climate factors and human activities in impacting vegetation dynamics during 2000-2015 in the Otindag Sandy Land, northerm China. Journal of Arid Land. 9(4): 558-567. doi:10.1007/s40333-017-0062-y

Mi, J., Li, JJ., Chen, DM., Xie, YC. (2015). Predominant control of moisture on soil organic carbon mineralization across a broad range of arid and semiarid ecosystems on the Mongolia plateau. Landscape Ecol, 30: 1683-1699.

Miao, LJ., Jiang, C., He, B., et al. (2014). Response of vegetation coverage to climate change in Mongolian Plateau during 10 years. Acta ecological since, 34(5): 1295-1301. doi:10.5846/stxb201304100659.

Mu, Q., Heinsch, FA., Zhao, M., et al. (2007). Development of a global evapotranspiration algorithm based on MODIS and global meteorology data.Remote Sensing of Environment, 111(4): 519-536.

Nicholson, SE., Tucker, CJ., Ba, MB. (1998). Desertification, drought, and surface vegetation: an example from the west African Sahel.Bulletin of the American meteorological society, 79(5): 815-829.

Okin, G., Murray, B., Schlesinger, W. (2001). Degradation of sandy arid shrubland environments: observations, process modeling, and management implications. Journal of Arid Environments, 47: 123-144.

Peng, J., Dong, WJ., Yuan, WP., et al. (2012). Responses of grassland and forest to temperature and precipitation changes in Northeast China.Advances in atmospheric sciences, 29(5):29:1063-1077. 
Rashid, R., Fang, Z., Rogier, DJ., et al. (2016). Global and Regional Variability and Change in Terrestrial Ecosystems Net Primary Production and NDVI: A Model-Data Comparison. Remote Sensing, 8(3): 177-.

SDGs. (2015).https://www.un.org/sustainabledevelopment/biodiversity/\#tab-cda296f4c42a3f5a888

Shi, S., Zou, XY., Zhang, CL., Su, G. (2009). Investigation of vegetation restoration in the area of Beijing and Tianjin sandstorm source control project. Science of Soil and Water Conservation, 7(2): 86-92. doi:10.16843/j.sswc.2009.02.015

Sternberg, T., Rueff, H., Middleton, N. (2015). Contraction of the Gobi Desert, 2000-2012. Remote Sensing, 7(2): 1346-1358.

Tong, YQ., Long, HL. (2003). Study on sustainable development in the poor areas coupled with vulnerable eco-environment. China Population, Resources and Environment, 13(2): 47-51.

UNCCD. United Nations Convention to Combat Desertification in Those Countries Experiencing Serious Drought and/or Desertification, Particularly in Africa; UN: Paris, France. 1994.

UNEP. World atlas of desertification 2ED. UNEP, London. 1997.

Wei, YJ., Zhen, L., Ocirbat, B., et al. (2009). Empirical Study on Consumption of Ecosystem Services and Its Spatial Differences over the Mongolian Plateau. Resources Science, 31(10): 1677-1684.

Wieder, W., Cleveland, C., Smith, W., et al. (2015). Future productivity and carbon storage limited by terrestrial nutrient availability.Nature Geoscience, 8: 441-444.

Xue, Y. (1996). The impact of desertification in the Mongolian and the Inner Mongolian grassland on the regional climate. Journal of climate, 9(9): 2173-2189.

Xue, Y., Shukia, J. (1993). The influence of land surface properties on Sahel climate. Part 1: Desertification. Journal of climate, 6(12): 2232-2246.

Yang, CF. (1997). Land degradation and its strategies in China.China environmental science, (2): 108-112.

Zhang, B., Tsunekawa, A., Tsubo, M. (2008). Contributions of sandy lands and stony deserts to long-distance dust emission in China and Mongolia during 2000-2006. Global \& Planetary Change, 60(3-4): 487-504.

Zhang, X., Gong, S., Zhao, T., et al. (2003). Sources of Asian dust and role of climate change versus desertification in Asian dust emission.Geophys. Res. Lett., 30(2): 65-72.

Zhang, XY., Hu, YF., et al. (2009). NDVI spatial pattern and its differentiation on the Mongolian Plateau. Journal of Geographical Sciences, 19: 403-415. Doi: 10.1007/s11442-009-0403-7.

Zhou, JS., Pu, LJ. (1996). The rustic opinions on both conception of desertification and its practical significance. Journal of desert research, 11(2): 191-195.

Zhu, ZD. (1994). Current situation and prospect of land desertification problem. Geographical research, 01: 104-113.

\section{Table}

Table 1 Scenarios of vegetation change and their causative factors

\begin{tabular}{lllll}
\hline Slope & Slope & Slope & Scenario and driving factors & Tag \\
\hline NDVI & NPP-p & NPP-RES & & \\
$<0$ & $>0$ & $<0$ & Vegetation degradation caused by anthropogenic factors & A \\
& $<0$ & $>0$ & Vegetation degradation caused by climatic factors & \\
& $<0$ & $<0$ & Vegetation degradation caused by climatic and anthropogenic factors & B \\
& $>0$ & $>0$ & Error 1: Vegetation degradation but both factors benefit vegetation recovery & B \\
$>0$ & $<0$ & $>0$ & Vegetation recovery caused by anthropogenic factors &
\end{tabular}




\begin{tabular}{lllll}
\hline Slope & Slope & Slope & Scenario and driving factors & Tag \\
\hline & $>0$ & $<0$ & Vegetation recovery caused by climatic factors & C \\
& $>0$ & $>0$ & Vegetation recovery caused by climate and anthropogenic factors & \\
$<0$ & $<0$ & Error 2: Vegetation recovery but both factors led to vegetation degradation & D \\
\hline
\end{tabular}

Table 2 Proportion of NDVI change in each subregion

\begin{tabular}{lllll}
\hline Period & Change & DSR & GSR & FSR \\
\hline $2000-2015$ & significant restoration (restoration) & $25.73 \%(86.99 \%)$ & $31.88 \%(91.81 \%)$ & $51.52 \%(88.42 \%)$ \\
& significant degradation (degradation) & $0.53 \%(13.01 \%)$ & $0.33 \%(8.19 \%)$ & $2.57 \%(11.58 \%)$ \\
$2000-2005$ & significant restoration (restoration) & $3.91 \%(73.13 \%)$ & $7.98 \%(64.08 \%)$ & $15.62 \%(59.11 \%)$ \\
& significant degradation (degradation) & $1.94 \%(26.87 \%)$ & $1.35 \%(35.92 \%)$ & $3.16 \%(40.89 \%)$ \\
$2005-2010$ & significant restoration (restoration) & $5.50 \%(63.36 \%)$ & $3.54 \%(55.10 \%)$ & $4.63 \%(60.85 \%)$ \\
& significant degradation (degradation) & $2.38 \%(36.64 \%)$ & $2.02 \%(44.90 \%)$ & $3.36 \%(39.15 \%)$ \\
$2010-2015$ & significant restoration (restoration) & $6.44 \%(51.71 \%)$ & $5.68 \%(69.40 \%)$ & $14.49 \%(73.16 \%)$ \\
& significant degradation (degradation) & $3.14 \%(48.29 \%)$ & $0.82 \%(30.60 \%)$ & $1.89 \%(26.84 \%)$ \\
\hline
\end{tabular}

Table 3 Proportion of vegetation change area caused by different driving factors in each region

\begin{tabular}{llll}
\hline Type & DSR & GSR & FSR \\
\hline Degradation via anthropogenic factors & $1.02 \%$ & $6.63 \%$ & $9.30 \%$ \\
Recovery via anthropogenic factors & $0.94 \%$ & $4.41 \%$ & $12.21 \%$ \\
Recovery via climate change & $0.48 \%$ & $13.98 \%$ & $18.24 \%$ \\
Degradation via anthropogenic and climate factors & $0.04 \%$ & $0.06 \%$ & $0.19 \%$ \\
Recovery via anthropogenic and climate factors & $0.46 \%$ & $4.64 \%$ & $8.79 \%$ \\
Error & $0.09 \%$ & $1.17 \%$ & $2.73 \%$ \\
\hline
\end{tabular}

Table 4 Policy measures for regional vegetation restoration after 2000

\begin{tabular}{|c|c|c|c|}
\hline Region & Policy measures & Project influence & References \\
\hline Mongolia & $\begin{array}{l}\text { The third reclamation of } \\
\text { abandoned farmland in } \\
\text { Mongolia in } 2005 \\
\text { Strategy of invigorating } \\
\text { the country via the } \\
\text { mining industry in } 2006 \\
\text { New edition of Mineral } \\
\text { Law in } 2006\end{array}$ & $\begin{array}{l}\text { Promote vegetation } \\
\text { restoration Balance } \\
\text { animal husbandry and } \\
\text { environmental protection. }\end{array}$ & Chen et al., 2015 \\
\hline China & $\begin{array}{l}\text { Beijing-Tianjin } \\
\text { sandstorm control project } \\
(2000) \text { The second round } \\
\text { of GTGP* in } 2007 \\
\text { Overall improvement of } \\
\text { land use in the third } \\
\text { round of GTGP in } 2014\end{array}$ & $\begin{array}{l}\text { Overall improvement of } \\
\text { land use in the project } \\
\text { area Completed } \\
\text { conversion area of } 2.3 \times \\
10^{4} \mathrm{~km}^{2}\end{array}$ & $\begin{array}{l}\text { Shi et al., } 2009 \text { Wei et } \\
\text { al., } 2009\end{array}$ \\
\hline
\end{tabular}


* The GTGP (Grain to Green Program) is an important program of natural ecological system restoration in China (Liu D et al, 2014), which aims at controlling soil and water loss, and improving the ecological environment quality.
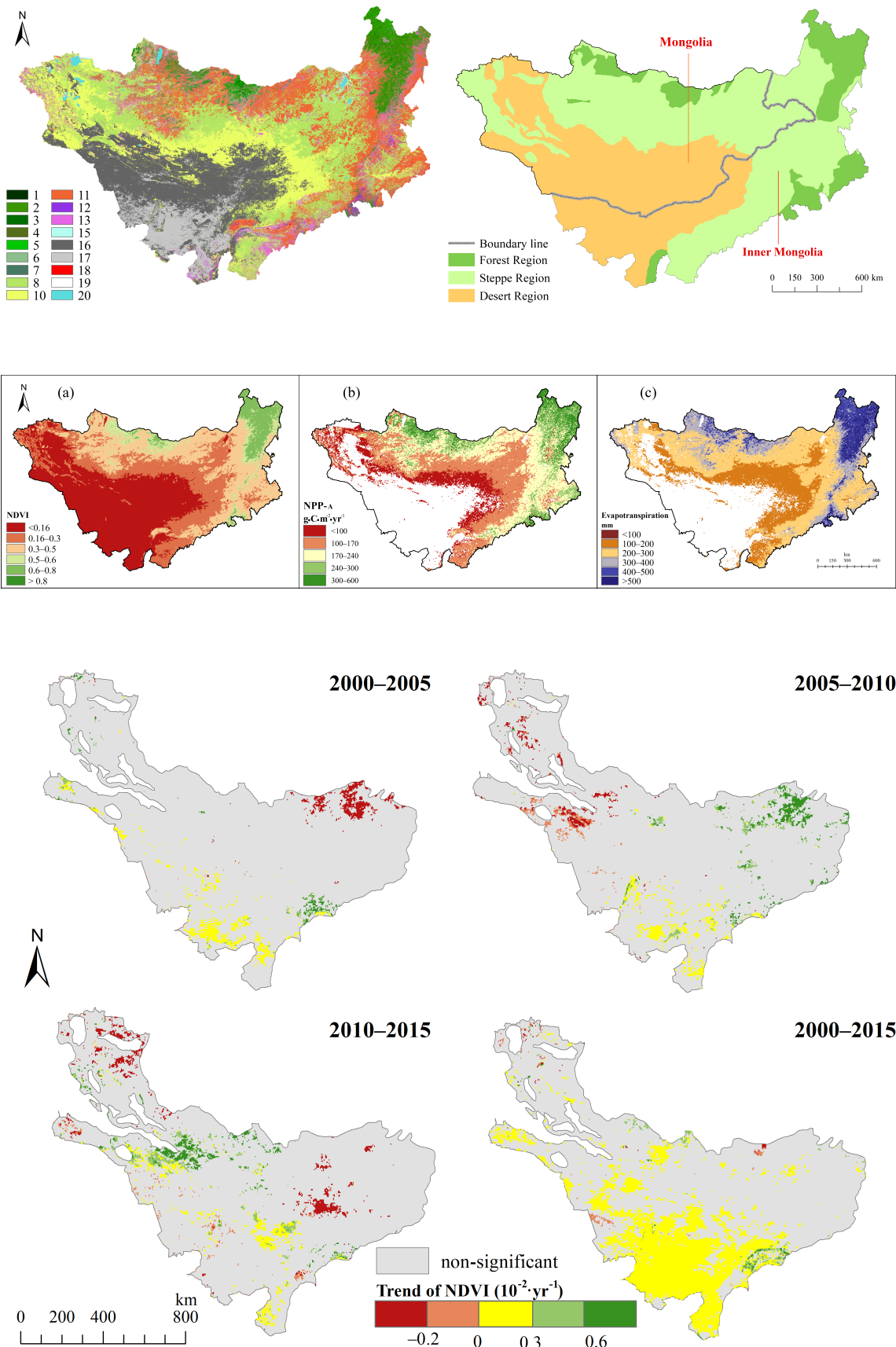

2010-2015

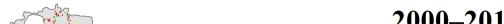

2000-2015 

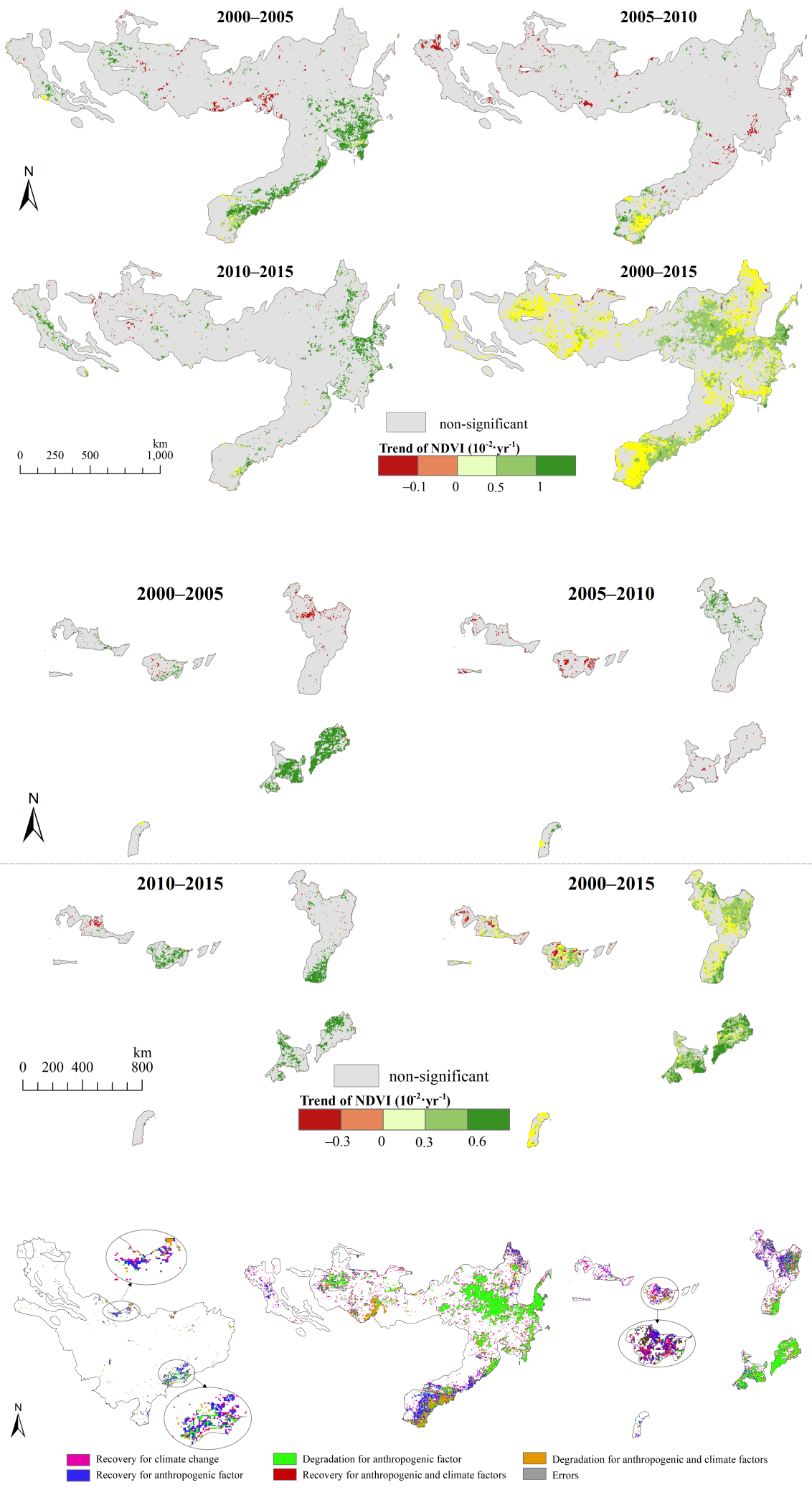